\title{
Association Between Patient Portal Use and Broadband Access: a National Evaluation
}

\author{
Jorge A. Rodriguez, $M D^{7}$ (1), Stuart R. Lipsitz, ScD ${ }^{7}$, Courtney R. Lyles, $P h D^{2,3}$, and \\ Lipika Samal, MD ${ }^{7}$
}

'Division of General Internal Medicine, Brigham and Women's Hospital, Boston, MA, USA; 2Division of General Internal Medicine, Department of Medicine, University of California San Francisco, San Francisco, USA; ${ }^{3}$ Center for Vulnerable Populations, Zuckerberg San Francisco General Hospital, University of California San Francisco, San Francisco, USA.

J Gen Intern Med 35(12):3719-20

DOI: $10.1007 / \mathrm{s} 11606-020-05633-4$

(c) Society of General Internal Medicine 2020

\section{INTRODUCTION}

Patient portals allow patients to access their own health information stored in the electronic health record (EHR). As a result of Meaningful Use (MU) program incentives, at least $88 \%$ of clinicians now offer a portal. ${ }^{1}$ Despite broad availability, portal use has lagged. The low uptake has been attributed to sociodemographic factors, including income, race/ethnicity, and education. ${ }^{2}$ However, a basic requirement for portal use is broadband internet access. The goal of our study was to correlate national data on broadband access with patient portal use in primary care.

\section{METHODS}

\section{Data Sources}

For the primary outcome, we used 2016 MU files, which contain responses to MU core measures for each eligible professional (EP) participating in the Medicare EHR Incentive program. ${ }^{3}$ We limited our analysis to primary care EPs. We linked this information with a combination of the National Provider Identifier, Google Maps Application Programming Interface, and the census geocoding service to identify the census tract identifier for each EP. This allowed us to determine the percentage of patients who have used the portal to either view, download, or transmit information as reported by EPs within each census tract. We adjusted for demographic characteristics at the census tract level using the American Community Survey 2016 and the 2013 Rural-Urban Continuum Codes from the U.S. Department of Agriculture. ${ }^{4}$ For broadband access

This study was presented at the Society of General Internal Medicine Annual Meeting in May 2019.

Received October 30, 2019

Accepted January 3, 2020

Published online January 10, 2020 information, we used the Federal Communications Commission (FCC) Form 477..$^{5}$

\section{Exclusion Criteria}

The MU reporting criteria excluded EPs who conducted $>$ $50 \%$ of encounters in a county that did not have broadband availability for over $50 \%$ of households. We excluded EPs if they (1) reported less than 10 patients (593), (2) practiced in Puerto Rico, Guam, or American Samoa (156), or (3) practiced in tracts without FCC data (1922).

\section{Analysis}

We performed generalized estimation equation analysis with clustering by census tract to assess the relationship between portal use and broadband access controlling for census tract demographics. Analyses were performed using R statistical software (version 3.4.3).

\section{RESULTS}

Our sample contained 67,190 primary care EPs representing 42,818,940 patients across 15,191 census tracts. At the census tract level, the mean reported rate of patient portal use was $28 \%$ (Table 1). Patients in census tracts with the lowest broadband access had a lower likelihood of using their portal (OR $0.64, p<0.001$ ). Multivariate results demonstrated an association between broadband access and portal use, even after controlling for sociodemographic variables (Table 2). Additionally, patients receiving care in census tracts with low education, low income, older populations, higher Hispanic population, or located in rural areas had decreased likelihood of portal use.

\section{DISCUSSION}

Despite nearly universal provision of patient portals, we have found that only about a third of patients are using them. Our findings are consistent with those of Perzynski et al. who 
Table 1 Census Tract-Level Demographics

\begin{tabular}{lc}
\hline \hline \% Male population, mean (sd) & $48.7(3.8)$ \\
$\%$ population $>65$, mean (sd) & $16.4(7.9)$ \\
$\%$ <high school diploma, mean (sd) & $4.3(4.8)$ \\
Median household income, mean (sd) & $\$ 62,541(\$ 28,966)$ \\
$\%$ Hispanic, mean (sd) & $11.9(16.0)$ \\
$\%$ White, mean (sd) & $78.2(19.8)$ \\
Broadband access & 5444 \\
Low $(0-400$ connections) & 5344 \\
Moderate (400-800 connections) & 4403 \\
High $>>800$ connections) & \\
Region ${ }^{\dagger}$ & \\
Rural & \\
Small town & 462 \\
Micropolitan & 791 \\
Metropolitan & 1395 \\
\hline
\end{tabular}

*Broadband access was defined as the number of residential fixed connections per 1000 households with a speed of at least 10 Mbps downstream/ 1 Mbps upstream by census tract. We collapsed the initial 6 categorical variables to 3 categorical variables

tWe collapsed the initial 9 categorical variables to 4 categorical variables

Table 2 Association Between Patient Portal Use and Broadband Access

\begin{tabular}{|c|c|c|c|c|}
\hline & \multicolumn{2}{|c|}{ Bivariate analysis } & \multicolumn{2}{|c|}{ Multivariate analysis } \\
\hline & OR & $p$ value & OR & $p$ value \\
\hline \multicolumn{5}{|l|}{ Broadband access (ref: high ( $>800$ connections) } \\
\hline Low $(0-400$ connections $)$ & 0.63 & $<0.001$ & 0.88 & $<0.001$ \\
\hline Moderate (400-800 connections) & 0.83 & $<0.001$ & 0.97 & 0.20 \\
\hline \multicolumn{5}{|l|}{ Region (ref: metropolitan) } \\
\hline Micropolitan & 0.64 & $<0.001$ & 0.74 & $<0.001$ \\
\hline Small town & 0.61 & $<0.001$ & 0.73 & $<0.001$ \\
\hline Rural & 0.59 & $<0.001$ & 0.70 & $<0.001$ \\
\hline Median household income* & 1.23 & $<0.001$ & 1.12 & $<0.001$ \\
\hline$\%$ population $>65$ years ${ }^{*}$ & 0.93 & $<0.001$ & 0.94 & $<0.001$ \\
\hline$\%$ population with less than a high school diploma ${ }^{*}$ & 0.87 & $<0.001$ & 0.94 & $<0.001$ \\
\hline$\%$ White ${ }^{*}$ & 1.01 & $<0.311$ & 0.99 & 0.370 \\
\hline$\%$ Hispanic $^{*}$ & 0.94 & $<0.001$ & 0.97 & 0.001 \\
\hline$\% \mathrm{Male}^{*}$ & 1.03 & $<0.001$ & 1.03 & $<0.006$ \\
\hline
\end{tabular}

* Standardized variable created by subtracting by the mean dividing by the standard deviation

found that only $29.1 \%$ of patients at an urban health care system used the portal. ${ }^{6}$

Our study highlights the impact of the lack broadband access on patient portal use. Given healthcare's increasing reliance on technologies, like portals and telehealth, broadband access has become a social determinant of health. Federal programs that subsidize broadband access, like Lifeline, offer potential solutions.

In addition to broadband access, we found that education, age, and race negatively impact portal use. These findings highlight disparities in technology implementation. Patientcentered design, training, and IT support are needed to increase portal use.

The primary limitation of our study is the use of provider census tract as a proxy for patient census tracts, which may not have equivalent demographics.

Our study promotes the importance of broadband equity in the dissemination of health technology, including portals, to all patients.

Corresponding Author: Jorge A. Rodriguez, MD; Division of General Internal Medicine Brigham and Women's Hospital, 1620 Tremont Street, Boston, MA, USA (e-mail: jarodriguez1@partners.org).
Compliance with Ethical Standards:

Conflict of Interest: The authors declare that they do not have a conflict of interest.

\section{REFERENCES}

1. Yocom C. HHS Should Assess the Effectiveness of Its Efforts to Enhance Patient Access to and Use of Electronic Health Information. United States Government Accountability Office. March 2017. https://www.gao.gov/ assets/690/683388.pdf.

2. Goel MS, Brown TL, Williams A, Hasnain-Wynia R, Thompson JA, Baker DW. Disparities in enrollment and use of an electronic patient portal. J Gen Intern Med. 2011;26(10):1112-1116.

3. Meaningful Use Data: Public Use Files. Meaningful Use Data: Public Use Files. https://www.cms.gov/Regulations-and-Guidance/Legislation/ EHRIncentivePrograms/PUF.html. Published October 10, 2018. Accessed September 12, 2019.

4. U.S. Census Bureau: American Community Survey. https://factfinder. census.gov/. Accessed September 12, 2019.

5. Form 477 Census Tract Data on Internet Access Services. Federal Communications Commission. https://www.fcc.gov/general/form-477census-tract-data-internet-access-services. Accessed September 12, 2019.

6. Perzynski AT, Roach MJ, Shick $\mathbf{S}$, et al. Patient portals and broadband internet inequality. J Am Med Inform Assoc. March 2017. doi:https://doi. org/10.1093/jamia/ocx020

Publisher's Note Springer Nature remains neutral with regard to jurisdictional claims in published maps and institutional affiliations. 